\title{
Time dependant functional and morphological recovery of the kidney after relief of obstruction in patients with impacted ureteral stones
}

\author{
Hüseyin Kocatürk ${ }^{1}$, Fevzi Bedir ${ }^{1}$, Ömer Turangezli ${ }^{1}$, Engin Ssebin ${ }^{2}$, Mehmet Sefa Altay ${ }^{1}$, \\ Banu Bedir ${ }^{3}$, Kemal Sarica ${ }^{4}$ \\ ${ }^{1}$ Department of Urology Health Sciences University, Erzurum Regional Training and Research Hospital, Erzurum, Turkey; \\ ${ }^{2}$ Department of Biochemistry Health Sciences University, Erzurum Regional Training and Research Hospital, Erzurum, Turkey; \\ ${ }^{3}$ Aziziye District Health Directorate, Erzurum, Turkey; \\ ${ }^{4}$ Biruni University, Faculty of Medicine, Department of Urology, Istanbul, Turkey.
}

\begin{abstract}
Summary
Objectives: To assess the course of functional and morphological recovery of the kidney following the relief of obstruction with ureteral JJ stent in cases with unilateral impacted stones.

Materials and methods: A total of 42 adult patients who were admitted to our clinic with unilateral obstructing impacted ureteral stones requiring JJ stent placement were included in the study. The course of functional recovery was assessed by evaluating the serum creatinine levels, renal resistive index (RRI) values and urinary levels of kidney injury molecule-1, neutrophil gelatinaseassociated lipocalin as well as microalbumin before at 1 day, 1 week and 4 weeks after JJ stent placement. Course of morphologic recovery was evaluated by evaluating the degree of hydronephrosis, kidney size, perirenal straining and ureteral diameter. Results: Our results showed that all relevant parameters began to decrease after 24 hours and continue to normalize during 1 week evaluation; majority of these variables indicating the functional and morphological recovery were in normal range after 4 weeks. Decompression of the obstructed kidneys with JJ stent placement in patients with impacted ureteral stones was found to be effective enough with recovery of normal renal functional and morphological status after a minimum time period of 4 weeks. Morphological recovery of affected kidneys following JJ stenting was obtained with a significant difference between baseline and 1 -month evaluation findings ( $p=0.001, p<001, p<001$, respectively). KIM-1 excretion began to decline to normal levels after 4 weeks $(3.52 \pm 0.99 \mathrm{ng} / \mathrm{ml}$ versus $2.84 \pm 0.66 \mathrm{ng} / \mathrm{ml}$, $p<0.001)$. The same findings were observed for the urinary excretion levels of NGAL, which normalized at the 1-month evaluation $(604.55 \pm 140.28 \mathrm{ng} / \mathrm{ml}$ versus $596.87 \pm 80.17 \mathrm{ng} / \mathrm{ml}$ $p=0.895$ ). Urinary microalbumin excretion levels however remained high even until 1-month follow-up with a statistically significant difference when compared with the normal excretion values $(p<0.001)$. There was a statistically significant difference in RRI values between baseline and 1-month follow-up findings in obstructed kidney $(p<0.001)$.

Conclusions: Elective management of the obstructing impacted ureteral stone(s) will be safer with limited risk of infective complications after functional and morphological normalization in such kidneys following 4 weeks of JJ stent placement.
\end{abstract}

KEY WORDS: Impacted ureteral stones; Renal function; Morphology; JJ stent; Obstruction.

Submitted 21 April 2021; Accepted 2 May 2021

\section{INTRODUCTION}

Urolithiasis is a very common disease that can affect all age groups and is seen in $1-13 \%$ of the general population depending on regional differences $(1,2)$.

Obstructing impacted ureteric stones require removal on time to decompress the upper urinary tract and to avoid possible renal functional, morphological alterations which may be irreversible in some cases $(3,4)$.

Depending on the departmental principles and surgeons preference, drainage of renal collecting system obstructed by such stones could be performed by placement of either a percutaneous nephrostomy tube or an indwelling ureteric stent. Both approaches are being accepted as equally effective by the EAU guidelines (5). Although randomized controlled studies could not demonstrate any significant difference between these two techniques, most urologists tend to insert a stent with this aim (6-8). Ureteral stenting is a commonly performed procedure to drain the collecting system particularly in cases with impacted stones in whom the spontaneous stone passage is less likely and the conservative medical management is ineffective. Additionally this approach is mandatory when evident hydronephrosis and infective symptoms are present (9-13). However, highly limited data is available regarding the course of renal functional and morphological recovery after stenting on a time dependant manner. Additionally no commonly accepted or established consensus is available regarding the optimal indwelling time of a ureteral stent in these cases. To our knowledge our study is the first evaluating the course of functional and morphological recovery following JJ stenting on a time dependant manner in cases with obstructive impacted ureteral calculi. Among the markers of renal damage, as a type-1 transmembrane protein, urinary kidney injury molecule-1 (KIM1 ) is not normally present in urine and its excretion has been found to increase as a valuable indicator of kidney injury along with histopathological changes in the proximal tubule in response to many pathophysiological states including obstruction. Again neutrophil gelatinase-associated lipocalin (NGAL), an iron-transporting protein was found to accumulate in urine rapidly after nephrotoxic and ischemic insults. It was used as an early, sensitive biomarker for 
acute kidney injury (14-16). Lastly, by providing information about the changes in microvascular blood flow, renal parenchymal doppler sonographic evaluation of the vascular impedance renal resistivity index (RRI) may be helpful in the asssessment of the functional or structural changes caused by acute and chronic obstructive renal diseases (1719). We aimed to evaluate the time dependant functional and morphological recovery of obstructed kidneys after JJ stenting in cases with impacted ureteral stones. Optimal time period for stenting to achieve a complete renal recovery following obstruction relief was also evaluated.

\section{MateriaLS AND MEthods}

\section{Study design and participants}

This prospective study was conducted in line with the ethical standards specified by the Declaration of Helsinki and following receipt of local ethical committee approval (2019/14-132). Informed consent was obtained from all individual participants included in the study. The data derived from 42 adult patients with a single impacted unilateral obstructing ureteral stone requiring JJ stent placement were evaluated in a prospective manner. Patients with bilateral, multiple stones, previous stone-related procedures, pregnancy, active urinary infection, renal tumour, congenital anomalies, solitary kidneys and a treatment of nephrotoxic drugs were excluded. Following the management of colic pain, in 42 cases with impacted ureteric stones obstruction has been decompressed by indwelling ureteral stenting. In addition to a non-contrast computed tomography (NCCT), plain X-ray of the kidney and urinary ultrasonography were also done to assess the degree of hydroneprosis and follow-up of the cases. Degree of hydronephrosis was graded as mild, moderate and severe. Kidney dimensions and the density (HU), size, side, localization of the stone and the diameter of the ureter above the stone were recorded. Patients with impacted obstructing ureteric stones with evident hydronephrosis were treated with a double J stent placement for an effective decompression and to evluate the functional as well as morphological changes on a time based manner. Following the stenting, the degree of hydronephrosis, perirenal staining and upper ureteral diameter were outlined on CT images and urinary ultrasonography to evaluate the course of morphologic recovery; the value of RRI assessed on Doppler sonography, urinary KIM-1, NGAL and urinary microalbumin levels were measured for functional recovery before, 1 day, 1 week and 4 weeks after JJ stent placement.

\section{Collection of urine specimens}

Midflow urine samples of the patients were obtained before, 1 day, 1 week and 1 month after the procedure. Urine $(10 \mathrm{~mL})$ was collected in plastic tubes, without any specific preservative. The urine samples obtained from all cases were centrifuged at 2000-3000 rpm for $20 \mathrm{~min}$ at $+4^{\circ} \mathrm{C}$. The supernatant urine samples were transferred to Eppendorf tubes. The samples were kept in a deep freezer system at $-80^{\circ} \mathrm{C}$ until analysis.

\section{Measurement of NGAL and KIM-1 in the urine}

The urinary NGAL and KIM-1 levels were measured with enzyme-linked immunosorbent assay (ELISA) method by using the human NGAL ELISA kit (Sunred Biological Technology Co., Ltd, Shanghai, China, Cat. No: 201-12-1720) and the human KIM-1 ELISA kit (Sunred Biological Technology Co., Ltd, Shanghai, China, Cat. No: 201-12-1100) in accordance with the manufacturer's instructions. The analysis was performed with a ChemWell ${ }^{\circledR}$ Automated EIA and Chemistry Analyzer device (Awareness Technology, Inc.; Miami, USA). Each sample was measured in duplicate and the obtained values were expressed as $\mathrm{ng} / \mathrm{ml}$.

\section{Measurement of blood urea nitrogen (BUN), creatinine and urinary microalbumin}

BUN, creatinine and urinary microalbumin were measured using Abbott kits on Architectc16000 (Abbott Diagnostics, Illinois, USA) device.

\section{Statistical analysis}

Recruitment and evaluation of the research data in this study was done by using Statistical Package fort the Social Science (SPSS) v24 for Windows program. Categorical variables were expressed with numbers and percentages; values, numerical variables were expressed with mean and standard deviation values. The consistency of the numerical variables to the analysis was searched by using Kolmogorov Smirnov Test. Mann-Whitney U and Chisquare tests were used in the evaluation of the obtained data, Friedman test was used in the comparison of the repeatedly assessed parameters without normal distribution, and lastly Wilcoxon Signed Rank test and Bonferoni correction were used for the comparison of the parameters within the group. Statistically significance value has been accepted to be $\mathrm{p}<0.05$.

\section{RESULTS}

In the group of 42 adult patients (> 18 years, M/F 3.6), mean age was $41.86 \pm 13.61$ (23-67) years, mean stone size was $10.16 \pm 1.99(7-14) \mathrm{mm}$. The overall mean body mass index (BMI) of these cases was $25.35 \pm 2.74$ (19.2$29.4) \mathrm{kg} / \mathrm{m}^{2}$. Majority of the stones $(40.5 \%$ ) was located in the upper ureter. Patient demographics along with stone related parameters are given in Table 1.

\section{Table 1.}

Patients' demographic features and stone characteristics.

\begin{tabular}{|l|c|c}
\hline & Mean $\pm \mathbf{S D} / \mathbf{n}(\%)$ & Median (min-max) \\
\hline Age & $41.86 \pm 13.61$ & $41(23-67)$ \\
\hline $\begin{array}{l}\text { Gender } \\
\text { Male } \\
\text { Female }\end{array}$ & $33(78.6)$ & \\
\hline BMI $\left(\mathrm{kg} / \mathrm{m}^{2}\right)$ & $9(21.4)$ & \\
\hline Stone side & $25.35 \pm 2.74$ & $25.60(19.20-29.40)$ \\
$\quad \begin{array}{c}\text { Right } \\
\text { Left }\end{array}$ & $22(52.4)$ & \\
\hline Stone size (mm) & $20(47.6)$ & \\
Stone localization & $10.16 \pm 1.99$ & $9.95(7-14)$ \\
$\quad$ Lower & $16(38.1)$ & \\
Mid & $9(21.4)$ & \\
Upper & $17(40.5)$ & \\
\hline Stone density (HU) & $649.60 \pm 207.66$ & $626.50(336-1016)$ \\
\hline BMI = Body Mass Index, HU = Hounsfield Units. & & \\
\hline
\end{tabular}


Table 2.

Kidney morphological parameters and Resistivity Index values.

\begin{tabular}{|c|c|c|c|c|c|}
\hline & $\begin{array}{c}\text { Pre-op } \\
\text { Mean } \pm S D \text { (min-max) }\end{array}$ & $\begin{array}{l}\text { Post-op (first day) } \\
\text { Mean } \pm \text { SD (min-max) }\end{array}$ & $\begin{array}{l}\text { Post-op (first week) } \\
\text { Mean } \pm S D \text { (min-max) }\end{array}$ & $\begin{array}{l}\text { Post-op (first month) } \\
\text { Mean } \pm S D \text { (min-max) }\end{array}$ & p \\
\hline Normal contralateral kidney RI & $\begin{array}{l}0.58 \pm 0.03 \\
(0.52-0.67)\end{array}$ & $\begin{array}{l}0.58 \pm 0.03 \\
(0.54-0.67)\end{array}$ & $\begin{array}{l}0.58 \pm 0.02 \\
(0.53-0.64)\end{array}$ & $\begin{array}{l}0.57 \pm 0.01 \\
(0.54-0.62)\end{array}$ & $p=0.407^{*}$ \\
\hline Obstructive kidney RI & $\begin{array}{l}0.74 \pm 0.04 \\
(0.66-0.83)\end{array}$ & $\begin{array}{l}0.62 \pm 0.02 \\
(0.54-0.73)\end{array}$ & $\begin{array}{l}0.59 \pm 0.02 \\
(0.53-0.64)\end{array}$ & $\begin{array}{l}0.58 \pm 0.02 \\
(0.55-0.63)\end{array}$ & $p<0.001^{*}$ \\
\hline $\begin{array}{l}\text { Normal contralateral kidney size } \\
\text { Long diameter }\end{array}$ & $\begin{array}{c}108.92 \pm 8.15 \\
90-128\end{array}$ & - & - & - & \\
\hline Transverse diamater & $\begin{array}{c}52.66 \pm 4.64 \\
44-62\end{array}$ & - & - & - & \\
\hline Parenchymal thickness & $\begin{array}{c}25.95 \pm 3.61 \\
19-32 \\
\end{array}$ & - & - & - & \\
\hline $\begin{array}{l}\text { Obstructive kidney size (mm) } \\
\text { Long diameter }\end{array}$ & $\begin{array}{c}111.69 \pm 9.51 \\
92-133\end{array}$ & $\begin{array}{c}110.73 \pm 8.59 \\
93-130\end{array}$ & $\begin{array}{c}110.54 \pm 8.15 \\
92-127\end{array}$ & $\begin{array}{l}109.92 \pm 7.94 \\
93-126\end{array}$ & $\begin{array}{l}p=0.002^{\mathrm{a}} \\
p=0.001^{\mathrm{b}} \\
p=0.00 \mathrm{~g}^{\mathrm{c}}\end{array}$ \\
\hline Transverse diamater & $\begin{array}{c}62.0 \pm 6.27 \\
48-72\end{array}$ & $\begin{array}{c}58.71 \pm 5.71 \\
46-69\end{array}$ & $\begin{array}{c}56.69 \pm 5.31 \\
45-68\end{array}$ & $\begin{array}{c}54.78 \pm 4.77 \\
45-65\end{array}$ & $\begin{array}{l}p<0.001^{\mathrm{a}} \\
p<0.001^{b} \\
p<0.001^{\mathrm{c}}\end{array}$ \\
\hline Parenchymal thickness & $\begin{array}{c}31.57 \pm 5.57 \\
21-43\end{array}$ & $\begin{array}{c}28.85 \pm 4.43 \\
20-39\end{array}$ & $\begin{array}{c}28.33 \pm 5.07 \\
20-48\end{array}$ & $\begin{array}{c}27.26 \pm 4.99 \\
20-46\end{array}$ & $\begin{array}{l}p<0.001^{\mathrm{a}} \\
p<0.001^{b} \\
p=0.002^{\mathrm{c}}\end{array}$ \\
\hline Ureter diameter (mm) & $\begin{array}{l}18.35 \pm 2.95 \\
(12.90-24.10)\end{array}$ & - & - & $\begin{array}{l}5.92 \pm 1.14 \\
(3.90-8.20)\end{array}$ & $p<0.001$ \\
\hline
\end{tabular}

\section{Morphologic recovery of the affected kidneys following JJ stent insertion}

Comparative evaluation of the baseline renal diameters of the affected kidneys with normal values revealed a statistically significant difference before and during early phase of the follow-up period ( $p=0.002, \mathrm{p}<0.001$, $\mathrm{p}<0.001$, respectively). Evaluation of values in the obstructed kidneys showed that while there was an insignificant difference between 1 day and 1 week evaluation $(p=0.637)$, a significant difference was noted between baseline and 1-month evaluation findings ( $\mathrm{p}=0.001, \mathrm{p}<001, \mathrm{p}<001$, respectively).

These findings emphasized the necessity of keeping JJ stent in place for at least a period of 4 weeks particularly in severely obstructed kidneys to catch the values of normal kidneys (108.92 $\pm 8.15 \mathrm{~mm}$ vs $109.92 \pm 7.94 \mathrm{~mm})(\mathrm{p}=0.566)$.

Evaluation of the mean ureteral diameter above the impacted stone site showed a significant decrease ( $p<0.001$ ) which came down to the normal size of a ureter after 4 weeks. Assessment of the hydronephrosis level in our cases revealed that while majority of the kidneys had a moderate or severe hydronephrosis (31\% and 69\%) prior to stenting; there was no or mild hydronehrosis detected during 1month follow-up evaluation. Detection of moderate hydronephrosis in a certain percent of these cases still during both 1 day (38.1\%) and 7 day (2.4\%) follow-up again showed the importance of keeping the stent in place for at least a month period. Similarly, the disappear- ance of perirenal staining (moderate to severe changes) required 4-weeks in obstructed kidneys. Morphological changes and related values in the obstructed kidneys are given on a time dependant manner in Tables 2, 3 .

\section{Evaluation of the functional recovery in obstructed kid- ney after JJ stent insertion}

Serum creatinine levels decreased significantly following JJ stent insertion after 7 days $(\mathrm{p}<0.001)$ and came down to normal levels at 1 -month follow up $(0.85 \pm 0.15 \mathrm{mg} / \mathrm{dL}$ vs $0.83 \pm 0.12$ respectively).

Additionally as demonstrated in Table 4, baseline urinary KIM-1 excretion continued to increase until the end of the first week after JJ stent insertion, and it returned to normal
Table 3.

Evaluation of the presence and degree of hydronephrosis and perirenal staining in study group cases.

\begin{tabular}{|l|c|c|c|c|}
\hline & No \% (n) & Mild \% (n) & Moderate \% (n) & Advenced \% (n) \\
\hline Hydronephrosis & & & & \\
Pre-op & - & - & $31.0 \%(13)$ & $69.0 \%(29)$ \\
Post-op (first day) & $2.4 \%(1)$ & $59.5 \%(25)$ & $38.1 \%(16)$ & - \\
Post-op (first week) & $9.5 \%(4)$ & $88.1 \%(37)$ & $2.4 \%(1)$ & - \\
Post-op (first month) & $57.1 \%(24)$ & $42.9 \%(18)$ & - & - \\
\hline Perirenal staining & & & & \\
Pre-op & $9.6 \%(4)$ & $19.0 \%(8)$ & $23.8 \%(10)$ & $47.6 \%(20)$ \\
Post-op (first day) & $11.9 \%(5)$ & $21.4 \%(9)$ & $28.6 \%(12)$ & $38.1 \%(16)$ \\
Post-op (first week) & $16.7 \%(7)$ & $54.7 \%(23)$ & $26.2 \%(11)$ & $2.4 \%(1)$ \\
Post-op (first month) & $81.0 \%(34)$ & $19.0 \%(8)$ & - & - \\
\hline
\end{tabular}


Table 4.

Evaluation of the urinary KIM-1, NGAL, microalbumin and serum BUN, creatinine levels.

\begin{tabular}{|c|c|c|c|c|c|}
\hline & $\begin{array}{c}\text { KIM-1 } \\
\text { Levels ng/ml }\end{array}$ & $\begin{array}{l}\text { NGAL } \\
\text { Levels ng/ml }\end{array}$ & $\begin{array}{l}\text { Urinary micro-albumin } \\
\text { Levels } \mathrm{ng} / \mathrm{ml}\end{array}$ & $\begin{array}{l}\text { BUN } \\
\text { Levels }\end{array}$ & $\begin{array}{l}\text { Creatinine } \\
\text { Levelsl }\end{array}$ \\
\hline $\begin{array}{l}\text { Pre-op } \\
\text { Mean } \pm S D \text { (min-max) }\end{array}$ & $\begin{array}{l}2.50 \pm 0.57 \\
(1.22-3.51)\end{array}$ & $\begin{array}{l}596.88 \pm 92.31 \\
(362.90-781.56)\end{array}$ & $\begin{array}{c}83.59 \pm 89.10 \\
(5.0-407.0)\end{array}$ & $\begin{array}{c}33.47 \pm 14.43 \\
(9.20-67.70)\end{array}$ & $\begin{array}{l}1.08 \pm 0.29 \\
(0.57-1.89)\end{array}$ \\
\hline $\begin{array}{l}\text { Post-op (first day) } \\
\text { Mean } \pm \text { SD (min-max) }\end{array}$ & $\begin{array}{l}3.52 \pm 0.99 \\
(2.11-6.15)\end{array}$ & $\begin{array}{l}761.16 \pm 137.85 \\
(483.80-1164.78) \\
\end{array}$ & $\begin{array}{c}335.54 \pm 94.30 \\
(167.0-500.0) \\
\end{array}$ & $\begin{array}{l}24.33 \pm 8.11 \\
(13.0-47.20)\end{array}$ & $\begin{array}{l}0.92 \pm 0.21 \\
(0.60-1.70) \\
\end{array}$ \\
\hline $\begin{array}{l}\text { Post-op (first week) } \\
\text { Mean } \pm \text { SD (min-max) }\end{array}$ & $\begin{array}{l}3.34 \pm 0.81 \\
(1.94-5.69)\end{array}$ & $\begin{array}{l}686.54 \pm 106.10 \\
(426.87-877.73)\end{array}$ & $\begin{array}{c}316.19 \pm 142.33 \\
(62.0-500.0)\end{array}$ & $\begin{array}{c}20.66 \pm 6.97 \\
(11.0-36.0)\end{array}$ & $\begin{array}{l}0.85 \pm 0.15 \\
(0.59-1.38)\end{array}$ \\
\hline $\begin{array}{l}\text { Post-op (first month) } \\
\text { Mean } \pm \text { SD (min-max) }\end{array}$ & $\begin{array}{l}2.84 \pm 0.66 \\
(1.56-4.46)\end{array}$ & $\begin{array}{l}604.55 \pm 140.28 \\
(333.29-959.15)\end{array}$ & $\begin{array}{c}159.66 \pm 112.66 \\
(23.0-452.0)\end{array}$ & $\begin{array}{c}20.91 \pm 8.11 \\
(10.0-38.0)\end{array}$ & $\begin{array}{l}0.83 \pm 0.12 \\
(0.61-1.08)\end{array}$ \\
\hline$\overline{\mathbf{p}^{1}}$ & $p<0.001$ & $p<0.001$ & $p<0.001$ & $p<0.001$ & $p<0.001$ \\
\hline$\overline{\mathbf{P}^{2}}$ & $p<0.001$ & $p<0.001$ & $p<0.001$ & $p=0.979$ & $p=0.769$ \\
\hline
\end{tabular}

levels after 4 weeks $(3.52 \pm 0.99 \mathrm{ng} / \mathrm{ml}$ vs $2.84 \pm 0.66$ $\mathrm{ng} / \mathrm{ml}, \mathrm{p}<0.001$ ).

The same findings were observed for the urinary excretion levels of NGAL which normalized at 1-month evaluation $(604.55 \pm 140.28 \mathrm{ng} / \mathrm{ml}$ vs $596.87 \pm 80.17 \mathrm{ng} / \mathrm{ml}$, $\mathrm{p}=0.895)$ following a significant initial elevation.

Evaluation of these two parameters demonstrated that the functional normalization of the obstructed kidney occurs after at least 4 weeks later following stenting.

Urinary microalbumin excretion levels however remained high even until 1-month follow-up with respect to normal excretion values (Table 4).

Lastly, while the assessment of RRI values of in normal contralateral kidneys didn't show any significant difference during follow-up $(p=0.407)$, there was a statistically significant difference between baseline and 1month follow-up findings in obstructive kidney ( $\mathrm{p}<$ 0.001 ) which came down to the levels of normal levels after 4 weeks (Table 2).

\section{Discussion}

Unilateral ureteral obstruction due to an impacted calculi is a common emergency status requiring a quick drainage of the upper urinary tract to avoid possible detrimental alterations in the kidney. Renal interstitial fibrosis is the characteristic pathological manifestation in such kidneys which is directly related to the level of obstruction and renal functional impairment $(15,20)$. Rational approach in such cases is the quick relief of obstruction by insertion of either a nephrostomy tube or an indwelling double J ureteral stent before making an elective treatment plan. Although placement of a nephrostomy tube directly into the dilated collecting system is considered to be a more effective and rapid drainage method, this approach is more invasive and not indicated particularly in cases under anticoagulant medication.

Thus, majority of the urologists conisder placing a double J stent as a safe and efficient way of decompression $(21,22)$. However, although limited, randomized comparative studies demonstrated that the efficacy of both approaches is equally acceptable $(6,7,21-24)$.

Effective decompression of the obstructed kidney by stenting will result in morphological and functional normalization prior to a planned stone removal procedure which will certainly increase the success rates and limit the possible infectious complications. Despite the effectiveness of the use of JJ stents with this aim is accepted, the optimal time duration of stenting for an adequate drainage has not been clearly outlined. No evidence based and commonly accepted time period has been reported for keeping the stents in place to obtain the complete normalized status of the kidneys. Most urologists tend remove stents after 1-2 weeks simply by checking the degree of dilatation of the upper urinary tract (25-27).

Current EAU and AUA guidelines contain no definite information for the optimal duration of stenting in such cases and practice patterns vary dramatically from 1 week to 3 months depending on the personal experience and also departmental principles $(5,9)$. Moreover, no particular clinical trial had been performed so far to outline the course of clinical recovery in these kidneys after stent placement where the urologists tend to remove the stents without having any idea about the functional and morphological status of the kidneys.

Shigemura et al. evaluated the infection related morbidity induced by JJ stents concluding that stents staying up to 2 weeks period have less risk of relevant problems (13). In another study evaluating the calcification risk on stent surface, Kawahara et al. found that stents kept in place for more than 3 months are associated with higher risk of calcification. Similar studies emphasized the relationship between time of stenting and encrustation risk of the stents $(28,29)$.

Among functional biomarkers of kidney, KIM-1 is a transmembrane protein that is undetectable in urine of the healthy cases, but its increased expression was found to be correlated with ischemic and nephrotoxic kidney injury. Additionally, its levels has been found to increase as a result of parenchymal damage induced by urinary obstruction (14-16). On the other hand, another reliable biomarker is NGAL, a $25-\mathrm{kDa}$ protein that is secreted by proximal tubular cells. Published data demonstrated that NGAL could also be used as one of the most reliable markers in the assessment of kidney injury after ischemic or nephrotoxic states among which urinary obstruction 
is the most common (16). Lastly, Doppler sonographic evaluation of the vascular impedance in the renal parenchyma was used be to evaluate the functional or structural changes induced by acute and chronic obstructive renal diseases (17-19).

In our study, JJ stent placement provided an effective decompression of the upper urinary tract in obstructed kidneys with adequate functional and morphological recovery after 4-weeks. Although most of the parameters began to decrease after 24 hours and continue to decrease at 1 week evaluation, the majority of these variables returned to normal range after 4 weeks period. In other words, keeping the stent in place for a minimum duration of 4 weeks (if there is no other indication for removal) seems to be important for the functional and anatomical recovery of the affected kidneys. Our findings constitute reliable and objective data regarding the optimal duration of stenting in cases with obstruction induced by impacted ureteral calculi. Early removal of the stent without complete elimination of the obstructive alterations will leave the kidney with residual functional deterioration and dilatation. This condition may compromise the outcomes of a planned elective surgery performed for the removal of obstructing ureteral stone(s).

Additionally as such approaches, namely shock wave lithotripy and ureteroscopy, have possible detrimental effects on the kidneys due to either direct tissue damaging effects or to the elevated intrarenal pressures, residual dilation and functional deterioration in such kidneys will make them more prone to infective complications which will be a main problem during postoperative follow-up period.

\section{Conclusions}

Impacted ureteral stones will cause obstruction associated changes in functioning kidneys and quick drainage by stenting is highly effective to limit the chance of such detrimental alterations. Our results indicated that decompression of the obstructed system will let these kidneys to obtain normal functional and morphological status after a mimimum time period of 4 weeks limiting the risk of infective complications after elective treatment. However, we believe that further studies including large case series are certainly needed.

\section{ACKNOWLEDGMENT}

Special thanks to Radiology Expert Dr. Muammer Altınkaynak for his helps on the radiological evaluation.

\section{REFERENCES}

1. Sorokin I, Mamoulakis C, Miyazawa K, et al. Epidemiology of stone disease across the world. World J Urol. 2017; 35:1301-1320.

2. Tiselius HG. Epidemiology and medical management of stone disease. BJU Int. 2003; 91:758-767.

3. Wood K, Keys T, Mufarrij P, Assimos DG. Impact of stone removal on renal function: a review. Rev Urol. 2011; 13:73-89.

4. Moe OW. Kidney stones. Pathophysiology and medical management. Lancet. 2006; 367:333-344.
5. Turk C, Neisius A, Petrik A, et al. Guidelines on urolithiasis. 2019; Available at: http://uroweb.org. Accessed: 20 April, 2020.

6. Pearle MS, Pierce HL, Miller GL, et al. Optimal method of urgent decompression of the collecting system for obstruction and infection due to ureteral calculi. J Urol. 1998; 160:1260-4.

7. Mokhmalji H, Braun PM, Martinez Portillo FJ, et al. Percutaneous nephrostomy versus ureteral stents for diversion of hydronephrosis caused by stones: a prospective, randomized clinical trial. J Urol. 2001; 165:1088-92.

8. Sammon JD, Ghani KR, Karakiewicz PI, et al. Temporal trends, practice patterns, and treatment outcomes for infected upper urinary tract stones in the United States. Eur Urol. 2013; 64:85-92.

9. Preminger GM, Tiselius HG, Assimos DG, et al. EAU/AUA: nephrolithiasis Guideline panel. 2007 guideline for the management of ureteral calculi. J Urol. 2007; 178:2418-2434.

10. Christoph F, Weikert S, Müller M, et al. How septic is urosepsis? Clinical course of infected hydronephrosis and therapeutic strategies. World J Urol. 2005; 23:243-7.

11. Zheng J, Wang Y, Chen B, et al. Risk factors for ureteroscopic lithotripsy: a case-control study and analysis of 385 cases of holmium laser ureterolithotripsy. Wideochir Inne Tech Maloinwazyjne. 2020; 15:185-191

12. Conort P, Doré B, Saussine C. Comité Lithiase de l'Association Françaised' Urologie (Guidelines for the urological management of renal and ureteric stones in adults). Prog Urol. 2004; 14:1095-1102.

13. Shigemura K, Yasufuku T, Yamanaka K, et al. How long should double J stent be kept in after ureteroscopic lithotripsy? Urol Res. 2012; 40:373-6.

14. Wasilewska A, Taranta-Janusz K, Debek W, et al. KIM-1 and NGAL: new markers of obstructive nephropathy. Pediatr Nephrol. $2011 ; 26: 579-86$.

15. Xie Y, Xue W, Shao X, et al. Analysis of a urinary biomarker panel for obstructive nephropathy and clinical outcomes. PLoS One. 2014; 9:e112865.

16. Devarajan P. Biomarkers for the early detection of acute kidney injury. Curr Opin Pediatr. 2011; 23:194-200.

17. Eryildirim B, Sahan A, Türkoğlu Ö, et al. Non-invasive evaluation of obstruction after ureteroscopic stone removal: Role of renal resistive index assessment. Arch Ital Urol Androl. 2020; 92:244247.

18. Darmon M, Schortgen F, Vargas F, et al. Diagnostic accuracy of Doppler renal resistive index for reversibility of acute kidney injury in critically ill patients. Intensive Care Med. 2011; 37:68-76.

19. Brardi S, Cevenini G, Giovannelli V, Romano G. Longitudinal prospective observational type study about determinants of renal resistive index variations in chronic renal failure patients treated with conventional medical and dietetic therapy. Arch Ital Urol Androl. 2017; 89:305-309.

20. Zul Khairul Azwadi I, Norhayati MN, Abdullah MS. Percutaneous nephrostomy versus retrograde ureteral stenting for acute upper obstructive uropathy: a systematic review and metaanalysis. Sci Rep. 2021; 23:6613.

21. Ramsey S, Robertson A, Ablett MJ, et al. Evidence-based drainage of infected hydronephrosis secondary to ureteric calculi. J Endourol. 2010; 24:185-9.

22. Lynch MF, Anson KM, Patel U. Percutaneous nephrostomy and 
ureteric stent insertion for acute renal deobstruction. Consensus based guidelines. Br J Med Surg Urol. 2008; 1:120-125.

23. Guercio S, Ambu A, Mangione F, et al. Randomized prospective trial comparing immediate versus delayed ureteroscopy for patients with ureteral calculi and normal renal function who present to the emergency department. J Endourol. 2011; 25:1137-41.

24. Chen Y, Feng J, Yue Y, et al. Externalized ureteral catheter versus double-J stent in tubeless percutaneous nephrolithotomy for upper urinary stones: a systematic review and meta-analysis. J Endourol. 2018; 32:581-588.

25. Damiano R, Autorino R, Esposito C, et al. Stent positioning after ureteroscopy for urinary calculi: the question is still open. Eur Urol. 2004; 46:381-387.
26. Dauw CA, Simeon L, Alruwaily AF, et al. Contemporary practice patterns of flexible ureteroscopy for treating renal stones: results of a Worldwide Survey. J Endourol. 2015; 29:1221-1230.

27. Torricelli FC, De S, Hinck B, Noble M, Monga M. Flexible ureteroscopy with a ureteral access sheath: when to stent? Urology. 2014; 83:278-281.

28. Kawahara T, Ito H, Terao $H$, et al. Ureteral stent encrustation, incrustation, and coloring: morbidity related to indwelling times. J Endourol. 2012; 26:178-82.

29. Kadihasanoglu M, Kilciler M, Atahan O. Luminal Obstruction of Double J Stents Due to Encrustation Depends on Indwelling Time: A Pilot Study. Aktuel Urol. 2017; 48: 248-251.

\section{Correspondence}

Hüseyin Kocatürk, MD (Corresponding Author)

kocaturk78@hotmail.com

Fevzi Bedir, MD

fevzibedir84@gmail.com

Ömer Turangezli, MD

omerturangezli@gmail.com

Mehmet Sefa Altay, MD

memsefaaltay@gmail.com

Department of Urology, Health Sciences University Erzurum Regional

Training and Research Hospital, 25070 Palandöken/Erzurum (Turkey)

Engin Şebin, MD

sebinengin@gmail.com

Department of Biochemistry, Health Sciences University Erzurum Regional

Training and Research Hospital, 25070 Palandöken/Erzurum (Turkey)

Banu Bedir, MD

banubedir89@gmail.com

Aziziye District Health Directorate, Erzurum (Turkey)

Kemal Sarica, MD

saricakemal@gmail.com

Biruni University, Faculty of Medicine, Department of Urology, Istanbul

(Turkey) 